\title{
ASYMPTOTIC BEHAVIOR OF THE EDGE METRIC DIMENSION OF THE RANDOM GRAPH
}

\author{
NinA ZUBRILINA \\ Department of Mathematics \\ Stanford University \\ e-mail: nina57@stanford.edu
}

\begin{abstract}
Given a simple connected graph $G(V, E)$, the edge metric dimension, denoted $\operatorname{edim}(G)$, is the least size of a set $S \subseteq V$ that distinguishes every pair of edges of $G$, in the sense that the edges have pairwise different tuples of distances to the vertices of $S$. In this paper we prove that the edge metric dimension of the Erdős-Rényi random graph $G(n, p)$ with constant $p$ is given by

$$
\operatorname{edim}(G(n, p))=(1+o(1)) \frac{4 \log n}{\log (1 / q)},
$$

where $q=1-2 p(1-p)^{2}(2-p)$.
\end{abstract}

Keywords: random graph, edge dimension, Suen's inequality.

2010 Mathematics Subject Classification: 05C12, 05C 80.

\section{REFERENCES}

[1] B. Bollobás, D. Mitsche and P. Pralat, Metric dimension for random graphs, (2012). arXiv:1208.3801

[2] G. Chartrand, C. Poisson and P. Zhang, Resolvability and the upper dimension of graphs, Comput. Math. Appl. 39 (2000) 19-28. doi:10.1016/S0898-1221(00)00126-7

[3] G. Chartrand, L. Eroh, M.A. Johnson and O.R. Oellermann, Resolvability in graphs and the metric dimension of a graph, Discrete Appl. Math. 105 (2000) 99-113. doi:10.1016/S0166-218X(00)00198-0

[4] V. Filipović, A. Kartelj and J. Kratica, Edge metric dimension of some generalized Petersen graphs, Results Math. 74 (2019) Article 182.

[5] F. Harary and R.A. Melter, On the metric dimension of a graph, Ars Combin. 2 (1976) 191-195. 
[6] S. Janson, New versions of Suen's correlation inequality, Random Structures Algorithms 13 (1998) 467-483.

doi:10.1002/(SICI)1098-2418(199810/12)13:3/4〈467::AID-RSA15〉3.0.CO;2-w

[7] M. Johnson, Structure-activity maps for visualizing the graph variables arising in drug design, J. Biopharm. Statist. 3 (1993) 203-236.

doi:10.1080/10543409308835060

[8] A. Kelenc, N. Tratnik and I.G. Yero, Uniquely identifying the edges of a graph: The edge metric dimension, Discrete Appl. Math. 251 (2018) 204-220. doi:10.1016/j.dam.2018.05.052

[9] S. Khuller, B. Raghavachari and A. Rosenfeld, Landmarks in graphs, Discrete Appl. Math. 70 (1996) 217-229. doi:10.1016/0166-218X(95)00106-2

[10] R.A. Melter and I. Tomescu, Metric bases in digital geometry, Computer Vision, Graphics, and Image Processing 25 (1984) 113-121. doi:10.1016/0734-189X(84)90051-3

[11] J.W. Moon and L. Moser, A matrix reduction problem, Math. Comp. 20 (1966) 328-330. doi:10.1090/S0025-5718-66-99935-2

[12] P.J. Slater, Leaves of trees, Congr. Numer. 14 (1975) 549-559.

[13] N. Zubrilina, On the edge dimension of a graph, Discrete Math. 341 (2018) 20832088. doi:10.1016/j.disc.2018.04.010 